Kasperowicz, R., Pinczyński, M., \& Khabdullin, A. (2017). Modeling the power

of renewable energy sources in the context of classical electricity system

Journal

transformation. Journal of International Studies, 10(3), 264-272. doi:10.14254/2071-

of International

Studies

$8330.2017 / 10-3 / 19$

\title{
Modeling the power of renewable energy sources in the context of classical electricity system transformation
}

\section{Rafał Kasperowicz}

Poznań University of Economics

Poland

Email:rafal.kasperowic@@ue.poznan.pl

\section{Marcin Pinczyński}

Universidad Pontificia Comillas - ICAI Madrid

Spain

Email:marcinpinc@gmail.com

\author{
Asset Khabdullin \\ Rudny Industrial Institute \\ Rudny, Kazakhstan \\ Email:aset85@mail.ru
}

Abstract. Many regions, not only in the Europe, introduce plans for the

Received:

April, 2017 modernization of energy systems so that in a few or several years most of the demand for electricity was being able to cover using renewable energy sources. The aim of this paper is to present the possibility of estimation of appropriate power supply based on the renewable energy sources in the context of the whole energy system in the annual balance, taking into account the technical and the economic optimization strategies. The article presents also the simplified structure of the $100 \%$ renewable energy system supported by energy storage systems and the production of synthetic fuels.

Keywords: renewable energy, electric power system, economic evaluation.

JEL Classification: Q42

\section{INTRODUCTION}

Currently, most of the energy systems in the world are based on fossil fuels. Since last decade there is an ongoing debate about the possibility of renewable energy based power system. At the beginning of this century, many scientists claimed that renewable energy sources can meet only a few percent of the energy demand of a country of the size of Germany. Then, when renewable energy entered the day-ahead market, the scientists wondered whether wind energy can participate in the balancing markets following the dayahead market. Nowadays the renewable energy has a visible share in the energy source, what is became an 
obvious fact (Gomez \& Escobra, 2014; Balitskiy et al., 2016; or Streimikiene et al., 2016; Nagaj, 2016; Kasperowicz \& Štreimikiené, 2016).

The use of renewable energy in conventional energy systems is not always associated with the reconstruction of the entire system. It is possible to power the system for $25 \%$ of fluctuating sources without major modification of the system, the problems appear only if one wants to create a system powered by nearly $100 \%$ by renewable energy, where the greater part of the energy comes from fluctuating sources. The perfect source of renewable energy from the system operator's point of view are the hydroelectric plants, where the power can be modulated in any way. In countries like Norway, Brazil and Venezuela more than $65 \%$ of the energy comes from hydropower (Gielen, 2012), unfortunately due to the topography and climate, most countries need to look for other renewable energy sources that are not as stable as hydropower. To obtain the stability of the system powered close to $100 \%$ by renewable energy the system has to be equipped with the possibility of energy storage, enable flexible energy demand and provide the possibility to process the energy surplus, e.g..: in bioenergy fuels that can be used in the transport or to produce energy again in some crisis situations. Another method of improving the stability of the energy system is the integration of district heating / cooling energy production system. The integration of both systems improves their efficiency, reduces the demand for fuel and eliminates energy fluctuations from sources like wind power (Mathiesen et al., 2015). Selection of appropriate power supply and storage capacity also plays an important role in operation and profitability of the entire system. The aim of this paper is to present the possibility of estimation of appropriate power supply based on the renewable energy sources in the context of the whole energy system in the annual balance, taking into account the technical and the economic optimization strategies. The article presents also the simplified structure of the $100 \%$ renewable energy system supported by energy storage systems and the production of synthetic fuels.

Pollitt and Anaya (2016) made an attempt to examine what "high shares of renewables" actually means and what the real challenges are in terms of market design. Their analysis was based on three case studies (Germany, the UK, and the State of New York). The authors investigated the ability of today's electricity markets to cope with high shares of renewables. They found that different countries follow different pathways (Germany illustrates a "just do it" approach, UK - decarbonization, New York State - distributed resources use) and thus face different trade-offs between security of supply, environment, and affordability. In all case studies markets are seen as the main vehicle for absorbing high shares of intermittent renewables. Neuhoff, Wolter and Schwenen (2016) discussed at the European example how power market design evolves with increasing shares of intermittent renewables. They investigated how short-term markets and system operation will have to be adapted to the different needs of renewable and conventional generation assets and flexibility options. The authors analyzed the trade-offs between a differentiated treatment of groups of technologies and synergies and efficiency in short-term system operation. They concluded that in terms of investment and re-investment, different technology groups may warrant differentiated treatment, reflecting different levels of publicly accessible information, grid infrastructure requirements, different strategic choices types, and capital cost shares in overall generation costs. Rosen and Madlener (2016) noticed that the share of fluctuating renewable energy resources is constantly increasing and the centralized organization of the today's energy system cannot adequately accommodate such decentralized electricity generation. The paper presents a new local reserve energy market design (applied to residential households), which can facilitate the operation and allow trading within microgrids, where households and other smallscale prosumers trade their self-produced energy. To achieve this, an auction market needs to be designed that takes into account the properties of both the technologies in use and the household-traders, where users enjoy bidding and selling their energy. 


\section{THE STRUCTURE OF SYSTEM SUPPLIED WITH 100\% RENEWABLE ENERGY SOURCES}

The structure of the energy system powered by $100 \%$ by renewable energy sources suggested above is a simplified model designed for micro grid as well as for regional or national scale systems. A characteristic feature of the system is the fact that the energy surplus is converted into bioenergy fuels (methanol / DME via electrolysers) and used for heating (Lund, et al. 2011). The manufacturing process of the bioenergy synthetic fuels utilizes a part of carbon dioxide contained in smog or other chemical processes.

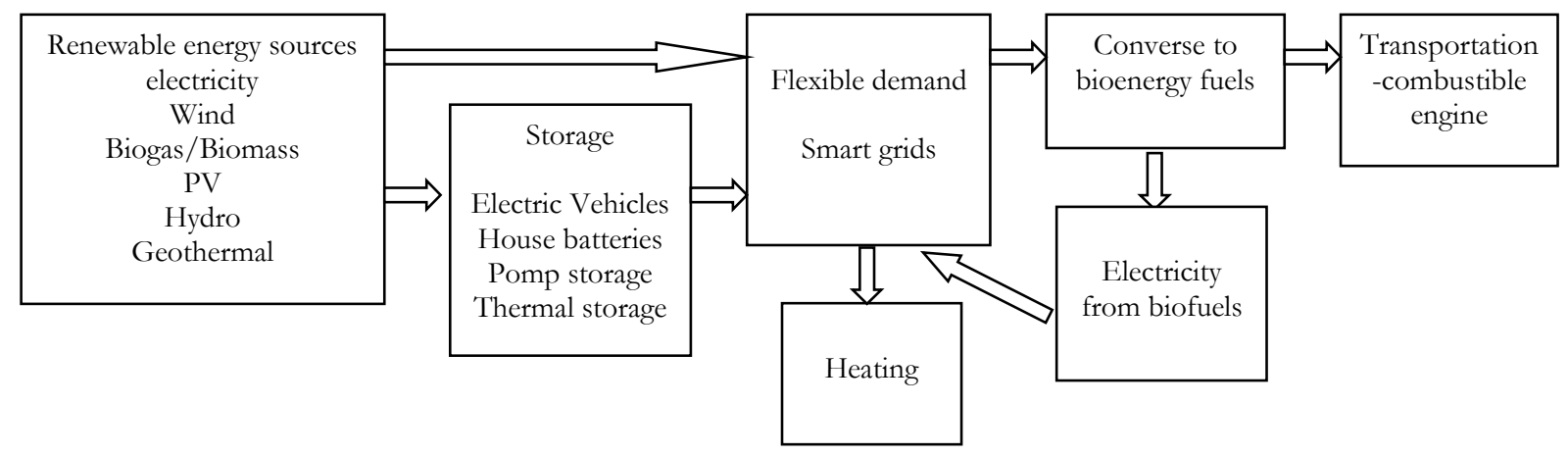

Figure1. The structure of system supplied with $100 \%$ renewable energy sources

One of the most important elements of the proposed system is the storage of energy through the use of modern electric vehicles (Lund, 2008) and household batteries for the storage it is possible to provide system stability during the peaks of energy demand which cannot be covered by the renewable energy sources (wind, PV, solar, etc.). The basic assumption of the system is to transfer energy directly from the producing source to the recipient, in situations of overproduction or deficiency of energy the auxiliary systems like storage or conversion to bioenergy fuels is to be used. An important role in this system plays the possibility of modulating the demand for energy by flexible demand. This solution is based on the smart grid such that the system can in a certain way to increase energy demand by switching some energy receivers or decrease the energy demand by disconnecting selected receivers from the grid. The choice of receivers that are involved in the flexible demand is defined by the appropriate algorithm (Petruzzi, IEEE, 2013; Ravindran, IEEE, 2014).

\section{METHODOLOGY OF THE CONDUCTED SIMULATIONS}

The analyzes are conducted in hourly steps for the entire year and in dependence on the chosen strategy. The first presented strategy is the market economic optimization, the second strategy is based on the technical regulation. The estimated simulation model basic inputs are: the demands, RES, energy capacities, parameters of the generator technology and costs. The outcome is the annual price of energy for the entire system.

\subsection{Market economic optimization}

The economic strategy is modeled on the operation of some European day-ahead markets, for example Spanish or Scandinavian, which are based on short-term marginal price and focus on the bids placed on the market to minimize short-term electricity cost for the consumer. The market price of energy is determined for each hour and results from the demand and supply of electricity. This strategy uses only variable costs 
and it does not optimize the long-term individual energy sources. The presented strategy looks for the cheapest methods to meet the demand by analyzing the economic and price of each productions units, taking into account that all the units maximize profits (Ostergaard, 2015; Lund, 2014).

\subsection{Technical optimization}

The strategy of technical optimization is based on the minimization of import and export of electricity and is focused on searching for a power source with the maximum fuel demand capacity. Renewable sources of energy such as offshore wind, PV and wind power have the priority in production. The minimum power share of the manufacturers who are responsible for the stability of the system frequency is required and taken into account (Ostergaard, 2015; Lund, 2014).

All the simulations were made using EnergyPLAN software.

\section{ANALYSIS OF THE SELECTION OF OPTIMAL POWER SUPPLY SOURCE - ECONOMIC CRITERION}

The selection of optimal proportions as to energy sources plays a vital role in the process of structuring of an electric power system. Such proportions are crucial not only in case of projecting a system in $100 \%$ based on the RES but also as regards mixed systems in which the RES provide only a part of the whole energy supply. As a rule, the simulations related to the selection of appropriate proportions as to the elements of the RES energy sources can be divided into two categories: simulations based on economic parameters and simulations based on technical parameter. The figure below presents a simulation of the selection of optimal offshore wind turbine power, in which the annual total cost of energy is the deciding parameter. The analysis considers average annual wind intensity. The sources in the simulation have a defined capacity: wind onshore 465 MW, photo voltaic 1085 MW, wave power 775 MW, whereas the optimal capacity of offshore wind is demanded.

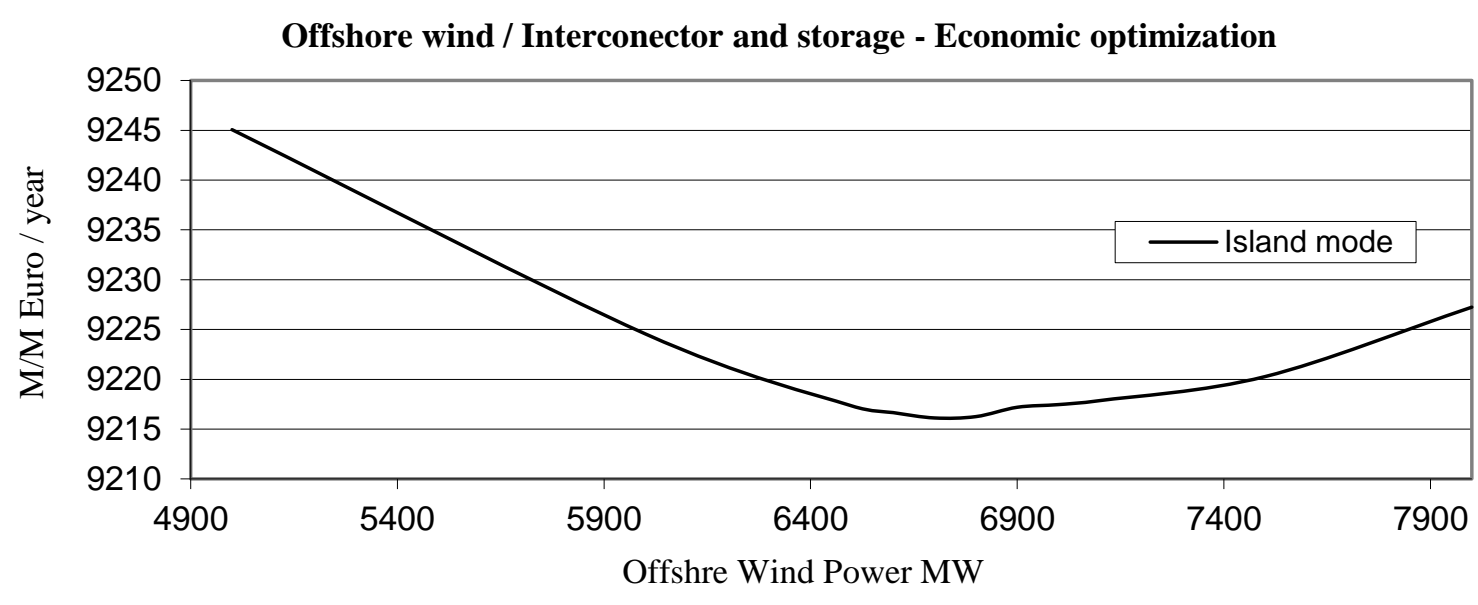

Figure 2. Dependence of the power of an offshore wind power plant on the annual price of the whole electricity in the system - the system is closed (island mode), there is no possibility to export any surplus 
The above figure 2 confirms that $6700 \mathrm{MW}$ would be the optimal power of offshore wind power plant because the annual energy costs for the whole system are the lowest and amount to 9217 million euro. The above costs encompass also savings related to the necessity of using less biomass and biofuels as well as to the cost of building a $6700 \mathrm{MW}$ power plant (the calculated wind power plant amortisation - 25 years).

The conducted analysis related to the selection of the optimal energy supply power of a given source, in this case - offshore wind power plants, indicates that a wrong selection of an energy supply capacity may greatly influence the energy costs in the whole system. Furthermore, it shall be considered that if it is not possible to use the whole power, designing an energy supply source with a greater power serves no purpose since it increases the energy costs in the whole system. It shall be also noted that supplying power from a selected energy source with a smaller power leads to the increase if energy costs of the whole system. The figure 2 clearly illustrates that an increase of installed power compared to the optimal power by $500 \mathrm{MW}$ results in an increase of energy price per year and system-wide by 10 million euro. Further, installing a source with a power that is lower than the optimal power by $500 \mathrm{MW}$ also leads to an increase of energy costs by 10 million euro per year and system-wide. It shall be further noted that the profitability of a system in a given localisation is influenced not only by the installed power but also by annual average wind intensity, connections enabling energy export, storing systems, energy demand etc.

\subsection{Analysis of offshore energy power system with a possibility of exporting and import energy}

The above figure depicts a system with parameters identical as the one in the paragraph 2, however, it is enriched with a possibility of energy export through an interconnector with a capacity of $400 \mathrm{MW}$. As shown in the figure 3, the system profitability changes significantly if there is a possibility to export and import some energy. The figure further shows that a deficiency of power supply triggers the same energy costs as in the case of a system with an interconnector; nevertheless, as soon as the optimal level for a closed system is reached, the energy prices decrease and range between from the optimal power and the optimal power plus the interconnector capacity $(6700+400 \mathrm{MW})$. The prices are falling down due to the fact that the energy export generates revenue, thus the built energy sources are even more profitable. However, if the energy source capacity increases above the optimal power plus interconnector capacity, annual energy prices increase once again. The above analysis illustrates how crucial the selection of optimal system parameters could be, in particular since a change of only one of the parameters may influence the profitability of the whole system.

Country-wide the electricity systems are very complex, have different variables which have impact on each other (changes of sun exposure, wind intensity, energy demand, temperatures etc.). A significant element securing the stability of a system powered in 100\% from the RES is ensuring appropriate possibilities of energy import/export as well as energy storing. 


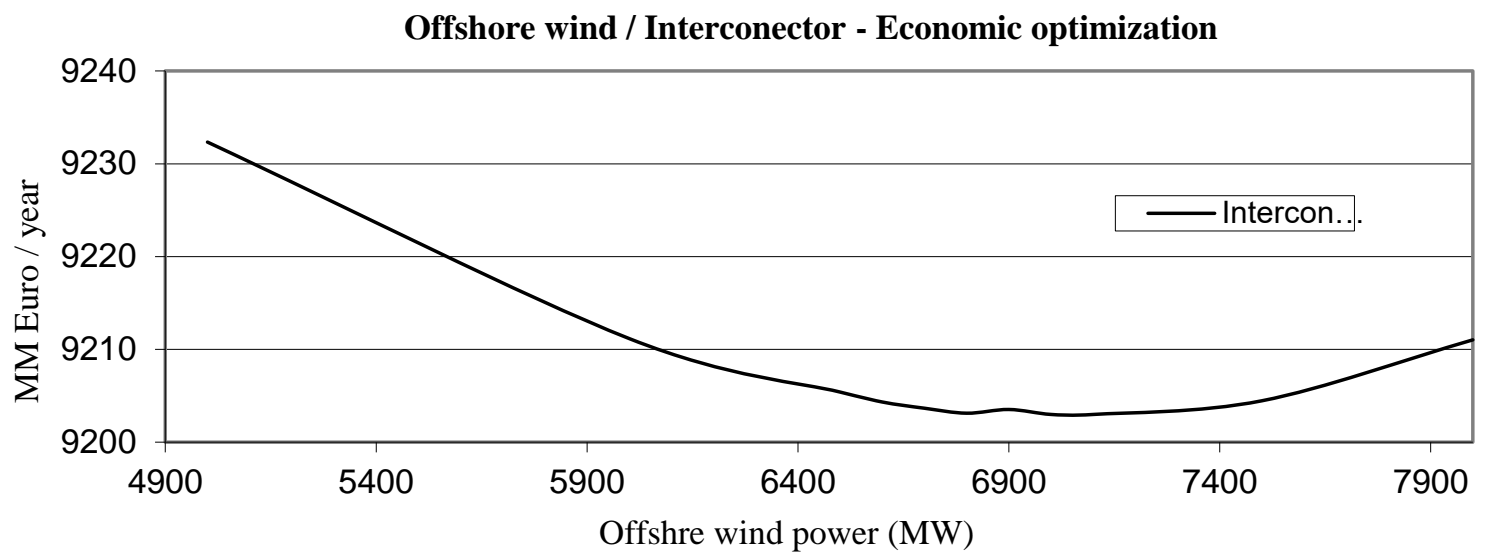

Figure 3. Dependence of the power of an offshore wind power plant on the annual price of the whole electricity in the system - open system, with a possibility of exporting surpluses

\subsection{Analysis of offshore energy power system with a possibility of exporting energy}

If a possibility of energy storing is added to the model proposed in point 3.1, such system will become more complex, while the profitability will no longer depend solely on the capacity of the supply source and the interconnector; it will be depending on the capacity of energy storing devices and storing costs.

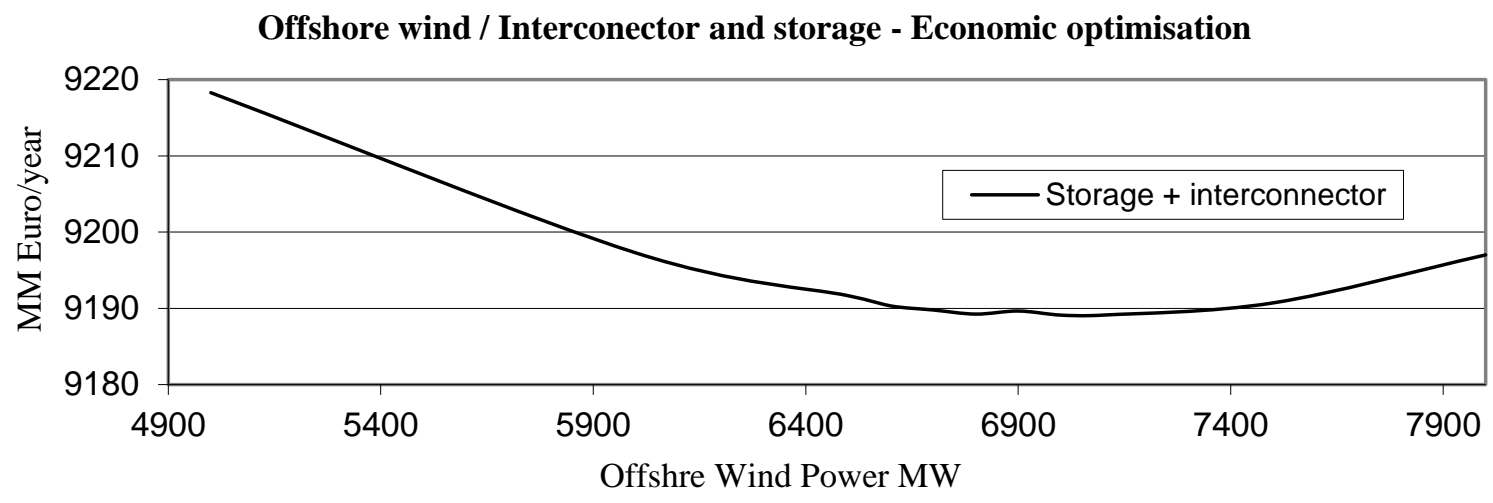

Figure 4. Dependence of the power of an offshore wind power plant power on the annual price of the whole electricity in the system - open system, with a possibility of exporting and storing surpluses

Due to the fact that in the proposed system the energy is stored in electric vehicles and home battery storages, the operator does not bear any costs with regard to the purchase and amortization of the abovementioned energy storage devices, therefore, the analysis does not include the costs of batteries purchase and its amortization. In the presented analysis, it is assumed that the battery performance amounts to $80 \%$ while the storing costs in the form of a fee for battery owners amount to $20 \%$ of the storage price of $1 \mathrm{KW}$. The level of battery capacity is assumed to amount to $500 \mathrm{MW} / \mathrm{h}$ which equals to 50000 of electric cars or home battery storages with a capacity of $0,01 \mathrm{MW} / \mathrm{h}$, connected to the grid in the mode of storing and returning the energy. Pursuant to German forecasts (Willenbacher, 2014), in the year 2026 in Germany ca. 1 million electric cars will be available, while only one-tenth of this amount will be required in order to 
maintain the stability of electricity system. Further, the new technologies of production of high-capacity batteries increases its profitability. Since the year 2015 the batteries with a capacity of $0.01 \mathrm{MW} / \mathrm{h}$ and with a lifetime warranty amounting to 10 years have been available at the price of $c a .3500$ dollars (tesla). Thanks to the new energy storing technologies, the renewable energy sources have broader applications to macro and micro grid.

The graph illustrates that the optimal supply power slightly decreased just as the energy price. The energy indispensable for the peaks in demand is partially generated from the battery. The storing profitability depends mainly on the storing costs and storing efficiency. On the basis of analyses conducted by Willenbacher (2014), the most optimal solution would be to produce energy onsite and in the time its demanded, therefore, both the number of transmission lines and the necessity of energy storing shall be reduced. Due to the variable characteristics of the renewable energy sources (wind, sun, water), in each system the energy storing solutions and interconnectors are indispensable for the stability of the whole system (Ding, 2010).

\section{ANALYSIS OF THE SELECTION OF OPTIMAL POWER SUPPLY SOURCE - TECHNICAL OPTIMIZATION}

Technical optimization in contrast to the economic optimization does not take into account only the price parameters, but also focuses on the technical limitations of individual power sources as well as the entire system. Its objective is to reduce the import and export of energy and fuel consumption. Technical optimization maps much more the real functioning of the entire energy market.

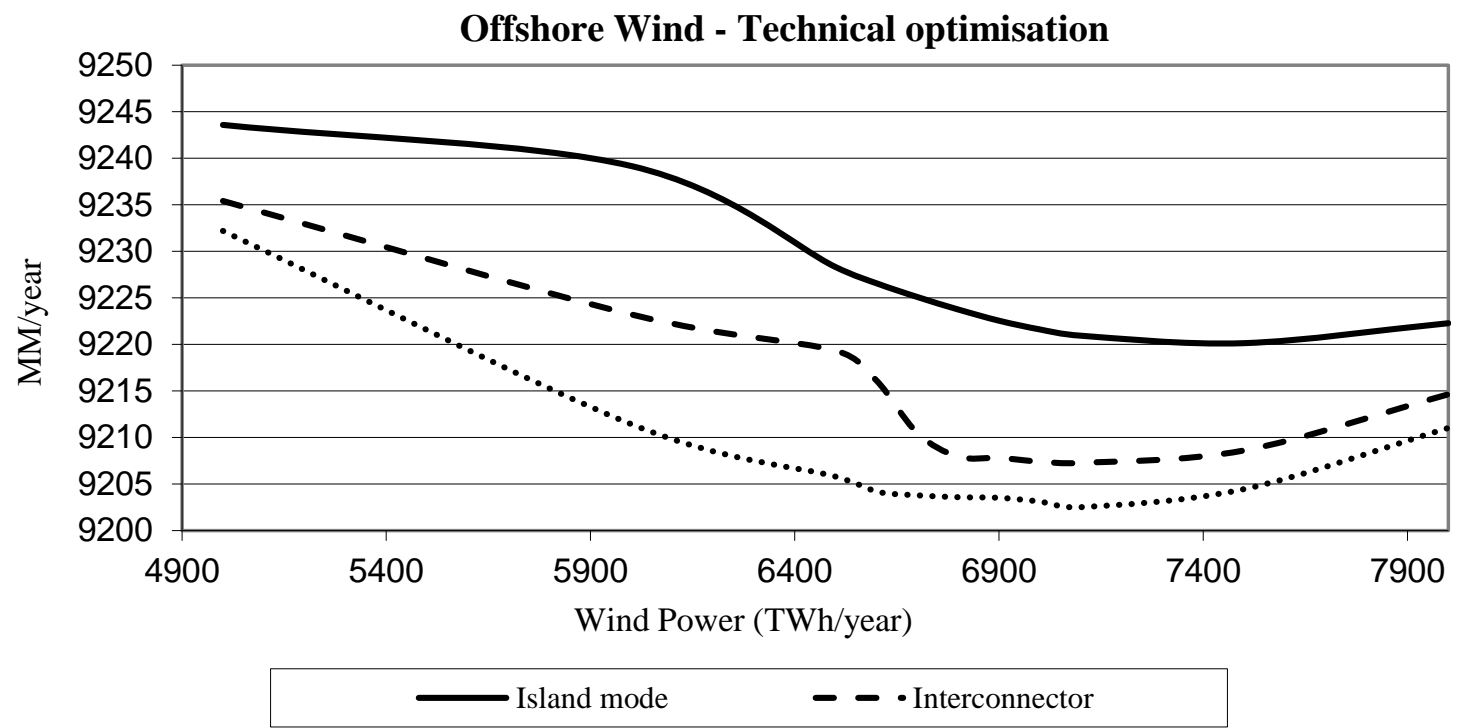

Figure 5. Dependence of the power of an offshore wind power plant power on the annual price of the whole electricity in the system

The price dependence of the power of power supply source presented in figure 5 refers to the system with the same parameters as in step 3 (Interconector $400 \mathrm{MW}$, Storage $500 \mathrm{MW} / \mathrm{h}$ ), but with the applied technical optimization. 
Technical optimization, due to its complexity, has less price effect in the year balance compared with the economic optimization and greater price volatility, what is connected with the attempts to limit export and import of energy (see graph 2-5). It should be emphasized that at the same time the enlargement of the system through the possibility of energy storage causes a significant drop in energy prices in the year balance and contributes to the reduction of price fluctuations relative to the change in the power supply (Figure 5).

\section{CONCLUSIONS}

The selection of the proper power supply sources plays a crucial role in the profitability of the entire system. From our analysis, we can clearly conclude that deficiency of power supply causes an increase in the annual price of energy of the entire system. However, the choice for high power supply may cause an increase in price of energy in the entire system due to the much higher costs associated with the construction and maintenance of additional power, which is not used. Taking into consideration the minimizing of the cost of energy an important element of each system is to equip the system with interconector that allows to export surpluses and import deficiencies of energy. With the development of energy storage techniques in car batteries or household batteries the price of energy in the entire system may decrease, because the grid operator does not bear the costs associated with the purchase and maintenance, use the stored energy only when it is necessary and then pays for the stored energy. Thanks to batteries the problems associated with too large power supply or power deficiency can be alleviated and the price variations will be lower. From the technical point of view the use of storage systems also increases the stability of the entire system. Further studies related to the appropriate choice of RES power supply related to the price of energy should focus on domestic renewable energy sources and the use of storage systems.

\section{REFERENCES}

Balitskiy, S., Bilan, Y., Strielkowski, W., \& Štreimikiene, D. (2016). Energy efficiency and natural gas consumption in the context of economic development in the European Union. Renewable and Sustainable Energy Reviews, 55, 156168.

Ding, J., \& Somani, A. (2010, April). A long-term investment planning model for mixed energy infrastructure integrated with renewable energy. In Green Technologies Conference, 2010 IEEE (pp. 1-10). IEEE.

Gielen, D. (2012). Renewable energy technologies: cost analysis series. Sol Photovolt, 1(1), 52.

Kasperowicz, R., \& Štreimikienè, D. (2016). Economic growth and energy consumption: Comparative analysis of V4 and the «old» EU countries. Journal of International Studies, 9(2), 181-194. doi:10.14254/2071-8330.2016/9-2/14.

Lisin, E., \& Strielkowski, W. (2014). Modelling new economic approaches for the wholesale energy markets in Russia and the EU. Transformation in Business \& Economics, 13(2B), 566-580.

Economics, L. (2007). Structure and performance of six European wholesale electricity markets in 2003, 2004 and 2005. Study for the European Commission.

Lund, H. (2014). Advanced energy systems analysis computer model. Aalborg University.

Lund, H., Hvelplund, F., Vad Mathiesen, B., Alberg Østergaard, P., Christensen, P., Connolly, D., ... \& Scott Bentsen, N. (2011). Coherent energy and environmental system analysis. Department of Development and Planning, Aalborg University.

Lund, H., \& Kempton, W. (2008). Integration of renewable energy into the transport and electricity sectors through V2G. Energy policy, 36(9), 3578-3587.

Nagaj, R. (2016). Changes in the regulation of the electricity sector as a factor in stimulating economic development in Poland in 2000-2014. Journal of International Studies, 9(1), 116-129. DOI: 10.14254/2071-8330.2016/9-1/8.

Neuhoff, K., Wolter, S., \& Schwenen, S. (2016). Power Markets with Renewables: New Perspectives for the European Target Model. Energy Journal, 37(SI2), 23-38.

Østergaard, P. A. (2015). Reviewing EnergyPLAN simulations and performance indicator applications in Energy PLAN simulations. Applied Energy, 154, 921-933. 
Pérez-Arriaga, I. J. (Ed.). (2014). Regulation of the power sector. Springer Science \& Business Media.

Petruzzi, P. E., Busquets, D., \& Pitt, J. (2013, September). Self organising flexible demand for smart grid. In Selfadaptation and self-organizing systems workshops (SASOW), 2013 IEEE 7th international conference on (pp. 21-22). IEEE.

Pollitt, M. G., \& Anaya, K. L. (2015). Can current electricity markets cope with high shares of renewables? A comparison of approaches in Germany, the UK and the State of New York. The Energy Journal, 37(2), 69-88.

Ravindran, P., Das, K. R., \& Mohan, A. S. (2014, March). Flexible demand response in smart grid based Automatic Generation Control. In Green Computing Communication and Electrical Engineering (ICGCCEE), 2014 International Conference on (pp. 1-6). IEEE.

Rosen, C., \& Madlener, R. (2014). Regulatory options for local reserve energy markets: Implications for prosumers, utilities, and other stakeholders. The Energy Journal, 37(2), 39-50.

Štreimikiené, D., Strielkowski, W., Bilan, Y., \& Mikalauskas, I. (2016). Energy dependency and sustainable regional development in the Baltic states: A review. Geographica Pannonica, 20(2), 79-87.

Willenbacher, M. (2014). My indecent Proposal to the German Chancellor. Verlag Herder GmbH. 